\title{
Problems of regulating financial markets as part of the green economy
}

\author{
Dilyara Abdrakhmanova ${ }^{1}$, Elena Karasik $^{1}$, Lenar Safiullin ${ }^{1,2, *}$, and Alexandra Scharonova ${ }^{3}$ \\ ${ }^{1}$ Kazan Federal University, Institute of Management, Economics and Finance, Kremlevskaya Street, \\ 18, Kazan, 420008, Russia \\ ${ }^{2}$ Center of Advanced Economic Research Academy of Sciences of the Republic of Tatarstan, 18 \\ Kremlyovskaya str., 420008, Kazan, Russia \\ ${ }^{3}$ St. Petersburg National Research University of Information Technologies, Mechanics and Optics, \\ 191002, St. Petersburg, Russia
}

\begin{abstract}
The development of economic processes in the contemporary world requires symmetrical efforts to guarantee the stability of markets as a whole and financial market in particular in the green economy. The development of financial markets happens depending on the evolution of economic systems and vice versa. In this connection, the issues of the adequate evolution of financial supervision become very urgent. The article considers the activity of the mega-regulator in Russia in the context of the world experience of active financial policy and regulation of financial markets in the green economy. The conceptual vision of the development of the mega-regulation of financial markets as immanent institute in the socioeconomic system is stated.
\end{abstract}

\section{Introduction}

As a result of the development of economic thought after the financial crisis, the most important questions are posed regarding the feasibility of the economic concept of markets and the behavior that has arisen during the last decades of the dominance of politicians in the management of the financial system. In response to this, some regulators begin to reexamine their understanding of the behavior of the subjects within financial markets.

Nevertheless, the basic concept of the dynamics of the markets themselves remains virtually unchanged. To regulate financial markets, we need more complex and more realistic cognitive structures with which we can analyze their dynamics and on the basis of which we can effectively regulate them [1].

The model of financial policy is important activity of a financial regulator. Modern studies show that various monetary interventions can have a different qualitative impact on the activity of setting up economic systems, and standard open market operations carried out by central banks have important multiplying consequences for revaluation in the economic system, in particular, having a beneficial effect on the level and distribution of material benefits and creating labor incentives for subjects and saving for retirement [2]. Effective banking system is the central section of the economy [3]. The question of the approach to the

\footnotetext{
*Corresponding author: lenar_s@mail.ru
} 
strategy for the formation of a national banking system will largely determine the future of socio-economic and social development. We have tried to investigate the listed and some other problems and questions in their interrelation in our work.

\section{Main Body}

The evolution of the macro-environment of financial markets, their multifactorial transparency [4] should be reflected in the increasing role of central banks as megaregulators. From September 2013, the Central Bank of Russia began to function as a megaregulator of financial markets. The combination of global factors and their multiple consequences, in particular, such as the amplitude of market fluctuations, cyclical economic trends, variable political instability, strongly influence the need for representation in the financial policy and regulation at the macroeconomic level of the system that is built during cognitive absorption of information for effective modeling of multi-factor impact on national financial markets in a green economy and economic system as a whole. The "main directions of the unified state monetary policy in 2015 and for the period of 2016 and 2017" approved by the Bank of Russia in November 2014 implies that the powers of the mega-regulator allow combining monetary policy measures with measures in the field of banking regulation and financial market regulation to achieve goals more effectively. The ultimate goal of the document is to increase and maintain a high level of citizens' welfare, which is the quintessence of state economic policy. At the same time, this document stipulates that when their parallel achievement is difficult, the Russian bank acts depending on the situation based on risk analysis and long-term assessment of consequences of their implementation.

This reservation is based on the understanding of the existence of an antagonistic principle in the nature of economic processes, as well as on the directions, tools and measures for the implementation of the multifunctional policy of the central bank. At the same time, it is widely known that dialectics, as a science of development, relies on the operation of the law of unity and the conflict of opposites. In this aspect, the concentration of system-forming functions in the combined mega-regulator contributes to the most effective integrated solution of this problem - the systemic convergence of financial policy and regulation in financial markets to stimulate the economy on a dialectical methodology. In particular, a favorable environment is created for the introduction of mechanisms to explain the empirical responses of the main macroeconomic variables during monetary and credit policy interventions [5].

The consolidation of the functions of the financial macro-regulator in the central bank of Russia will have a positive effect on dispersing the risks of the financial system [12]. Consolidation of financial market sectors in a single methodological field contributes to the harmonization of prudential standards and improves the quality of the regulatory functions of the central bank.

However, the mega-regulator will be able to solve more complex problems - intersectoral regulation and prudential supervision of systemically important market actors. In our opinion, the isolation of two levels of the regulatory environment will be methodologically justified. At the base systemically significant level, a single standardized methodological platform should be placed in the composite macrobase of the oversight requirements. Based on this, in the detailed, adaptive aspect of the diffusion of oversight requirements into the organizational and informational arrays of administrative calculations, protocols and procedures of business processes, corporate workflow, an effective structure should be built, which includes self-regulating organizations of market participants who can take upon themselves "last mile" to perform the functions of implementing system integration, as well as monitoring compliance with some of the more utilitarian requirements, standards. A twocomponent system (Fig. 1.) will allow the mega-regulator to focus during the combined 
regulation in the section of financial groups and in different sectors, where the level of uncertainty increases, and the risks become more complex and less predictable, and also create indicative supervision of systemically important companies in financial markets.

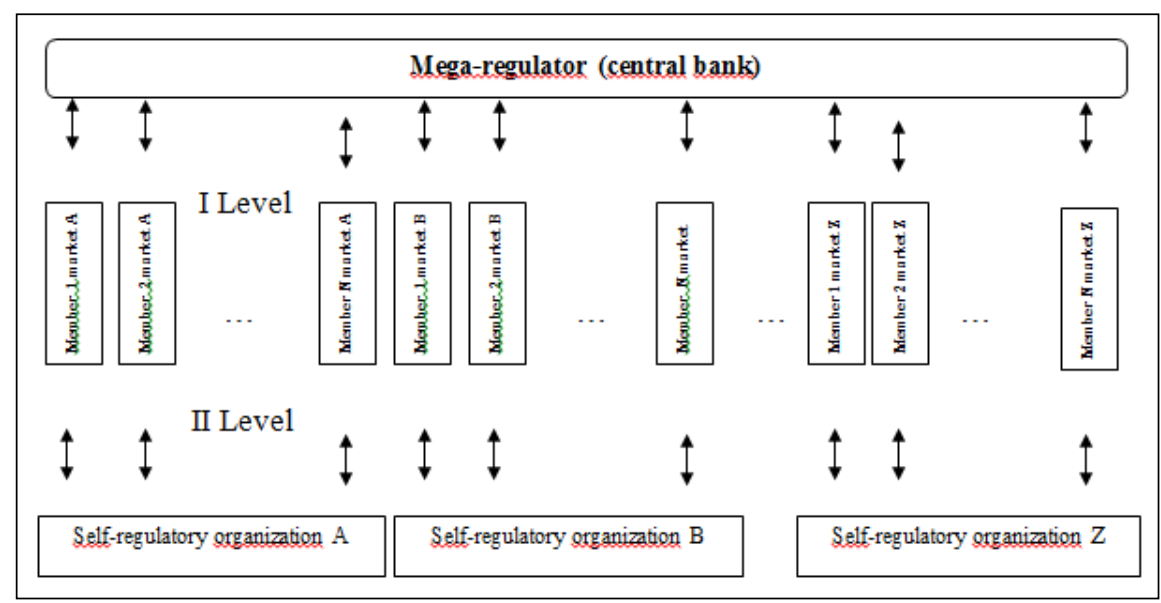

Fig. 1. The two-component system of the regulation of the financial markets.

At the same time, noting that the focus of attention of controlling, insurance and investment companies, non-state pension funds, microfinance organizations, in the remote region are still two quite significant segments of financial markets that fall outside the perimeter of the power of the mega-regulator - leasing and factoring. A palliative approach can reduce the macroeconomic effect. Of course, leasing and factoring companies are immanent participants of the financial market, their risks are mixed with the risks of the remaining players and, at a minimum, this is a reserve for expanding the mega-regulation perimeter. It is quite clear that it will be logical to supplement them in the near future with a system of prudential measures and requirements. It is quite possible that the value of the fastest creation of a global regulatory precedent experience entailed some more loss due to the incompleteness of the resulting system due to the lack of hardware resources. In our opinion, it is important to use a cognitive approach to understand the "incompleteness" in the construction and implementation of strategies. The mathematician Gödel formulated the incompleteness theorem - any finite axiom system is either incomplete or contradictory. Suppose you have a plan, and you assume that they have provided everything - needs, resources, feedback, etc. However, Gödel says: there will always be one ignored event in the system that will completely destroy it. Consequently, beyond the framework of axiomatic (isolated logic circuits), it is possible and necessary to act on the basis of a cognitive analysis of empirical experience. Extrapolating the aforementioned condition into the sphere of supervision over financial markets, let us assume that it would be a mistake to present the regulation as a finite set of rules and algorithms. Perhaps, for a more correct implementation, creating an adaptive, taboo-free, justifying, delicate control system with internal selfregulation mechanisms (according to the principle of economical built-in shock absorbers) would be proposed.

An example of flexibility and careful pedaling in matters of regulation is the transfer by the central bank the date of introducing a short-term liquidity index (referring to the Basel III system) from the planned January 1, 2015 by half a year until July 1, 2015 [6]. As you know, the basis of the risk management concept is the priority of the goal of stabilizing the administrative system. From this example, it is clearly seen that the principle of "causing of harm" is crucial in the implementation of the supervision policy. The delay is due to the politicized inspiration of external sources of distribution, which has led to problems in getting 
banks access to long-term resources. It can be said that the Central Bank of Russia revised the risk map by changing the period of introduction of the requirement, which helps the banking system to better prepare for the implementation of the norm. Of course, in addition to the sanctions outlined above, when making the decision, the entire set of factors of the macroeconomic situation in the country is taken into account. We also note that the multivariance is the main directions of the monetary policy of the central bank of Russia.

Today, Russia and the countries of the European Union are characterized by an increase in sovereign risk, which leads to a significant outflow of capital, external adjustments and compression of imports [7]. In this regard, the activities of the regulator cannot ignore foreign markets. Large macroeconomic potential lies in optimizing the management of capital movements - this is a source of increasing wealth and opening up regulatory opportunities as an instrument of financial policy to mitigate the inefficient use of resources, correct the structural imbalances of the economy and increase productivity [8].

Let's touch on some topical aspects of endogenous risks. The current credit financial markets of Russia are seriously concerned about the creation of universal debt restructuring systems involving the organizational capabilities of self-regulating organizations, in particular, associations of Russian banks. The discussion concerns the creation of a global database and the coordination of credit institutions in dealing with distressed debts. There are calls for the creation of a special restructuring product as a "packaged product", similar to a deposit and a loan product. Work is underway on the methodological, technological and organizational support of this direction.

Changes and innovations related to restructuring procedures are being introduced into the banking business processes system. That is, at the business planning level, a new form of activity is being introduced, resources are being shared, key indicators are being developed. In our opinion, such a direction of banking thinking is not fully effective from a strategic point of view, like encouraging mistakes in managing strategic risks at the organizational and technological level. It turns out that a high risk and low quality of active membership can be embedded in the existing administrative paradigm, and the efforts of managers are redirected to work with the consequences of this financial policy. There is a need for systematic assistance at the level of the regulator in all aspects: from methodological assistance in understanding the logic and feedback of the formation of business processes to administrative-regulatory tabulation through restrictive barriers. To the existing approaches to solving the problem of debt load - with the help of law and court or market and regulation [8], in our opinion, we should add an adaptive combination of tools and methods.

Speaking of systemic risks in the changed conditions - the consequences of crises, excessive derivatization of stock markets, bad debts, etc., financial markets in a green economy themselves need to evolve methods and approaches to regulation [9]. In this context, in our opinion, several questions could be formulated. Is it possible to create conditions for advanced regulation or is there a methodological barrier to constant movement after the tendency forced to react in a post factum mode? Will the upcoming actions not challenge the legislation on the protection of competition, antitrust and so on? Is there a risk of unconscious manipulation or imbalance of markets?

Without conducting an in-depth study within this article, let's express the opinion that the positive impact of mega-regulation will depend on the regulator's desire to concentrate on controlling risks in the financial system, and creating a system of motivation and incentives, without simply following standards, instructions and other tools of policies implementation, or on the strict limitation of banks and non-bank financial institutions by the possibility of various manipulations "on the verge" in order to avoid meeting the requirements of regulatory acts [10]. 
The value of analysis is achieved by its constancy. In 2015, the Russian bank plans to work out a draft of the main development directions and ensuring the stability of the financial market.

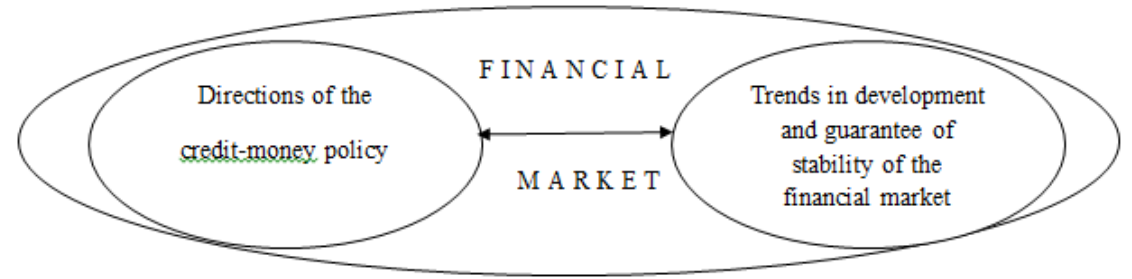

Fig. 2. Directions of the policy of mega-regulator on the financial market in Russia.

The appearance of this document will allow a more qualitative assessment of the strategic and tactical approaches of the mega-regulator. Based on this, many of the problems and questions presented in this article can get material for finding solutions and answers. At the same time, the analysis carried out, without claiming to be comprehensive, makes it possible to extract the main proposals and expectations. In our opinion, the factor of centralization of regulation and supervision in financial markets in a green economy can serve to achieve a synergistic effect from the consolidation of the apparatus, organizational and structural transformations, the acquisition of new incentive, justifying functions and the development of those that exist.

Conformity at the strategic level that was capable to smooth the influence of antagonistic toolkits, became possible through continuous information monitoring of financial policy convergence and regulatory measures in order to increase the efficiency of economic system. It may be necessary to think about a flexible hybrid method that is located outside the rigid definitional field and absorbs applied semantically multifunctional modeling of regulatory activity in the multidimensional behavior of economic systems. Modern conditions require creative, cognitive approaches [11] with a possible combination of previously considered antagonistic approaches in the opinion of orthodox from economic theory.

Thus, at first glance, the paradoxical antagonism of the postulated goals of fighting inflation and stimulating growth is solved by the Russian bank by extrapolating the chain of multiplied levers. It is clear that such a policy does not enable to obtain an immediate result; its effectiveness cannot be assessed by populists. But, in our opinion, this testifies to the maturation of the national economy, the qualitative development of its institutions and infrastructure, its ability to solve serious problems through a reasonable long-term policy rather than by command-and-control methods.

Table 1. Exemplary conceptual diagram of strategizing of the mega-regulator.

\begin{tabular}{|c|c|c|c|}
\hline Mission & Basic purposes & Basic functions & Modus of the action \\
\hline $\begin{array}{l}\text { Increase in the } \\
\text { welfare of the } \\
\text { citizens }\end{array}$ & $\begin{array}{l}\text { Targeting the } \\
\text { inflation, guarantee } \\
\text { of stable functioning }\end{array}$ & $\begin{array}{l}\text { Supervision, } \\
\text { regulation, the money } \\
\text { and credit policy }\end{array}$ & $\begin{array}{l}\text { Systemic cognitive } \\
\text { convergence of a } \\
\text { multifunctional mega- } \\
\text { regulation toolkit to } \\
\text { stimulate the economy }\end{array}$ \\
\hline
\end{tabular}

\section{Conclusion}

Overcoming the consequences of the financial crisis, countering today's challenges, dispersing the emerging complex multifactorial economic and financial risks in the future requires qualitatively new solutions in a systematic understanding of the mechanisms of 
functioning and evolution of financial markets. A problem of this magnitude can be effectively solved by creating a general dynamic monitoring of the economic and financial systems on the basis of the regulator of a universal integrated system. The information collected, penetrating into the cognitive analysis, should contribute to the formation of qualitative impulses of inter-sectoral regulation within the framework of a global balanced financial policy with subsequent convergence into economic growth stimuli. In a promising version, it is good to recreate the regulatory model as an integral part of the socio-economic and financial environment with the synergistic potential of adaptive self-development.

Formation on a single organizational and structural base of opportunities for consistently conducting harmonized financial policies across the economy will allow extrapolating the regulatory framework and principles of the financial system built into the banking core to the entire financial market.

\section{References}

1. J. Black, Journal of Corporate Law Studies 13(2), 401-442 (2013) ISSN 1473-5970

2. V. Sterk, S. Tenreyro The transmission of monetary policy operations through redistributions and durable purchases, CFM-DP2013-5 (Centre For Macroeconomics, London, UK, 2013)

3. S. Kapoor, C. Goodhart, Plans for a banking union may not be enough to tackle the eurozone's economic crisis (European Politics and Policy at LSE Blog Entry, 2013)

4. N. Johannesen, G. Zucman, American Economic Journal: Economic Policy 6(1), 65-91 (2014) ISSN 1945-7731

5. N.I. Larionova, Yu.A. Varlamova, Procedia Economic and finance 5, 737-746 (2013)

6. S.A. Bahaj, Systemic sovereign risk: macroeconomic implications in the euro area, CFM-DP2014-6 (Centre For Macroeconomics, London, UK, 2014)

7. S. Paterson, Journal of Corporate Law Studies 14(2), 333-365 (2014) ISSN 1473-5970

8. G. Benigno, L. Fornaro, Scandinavian Journal of Economics 116(1), 58-86 (2014) ISSN 1467-9442

9. L.N. Safiullin, A.Z. Novenkova, N.Z. Safiullin, Procedia Economic and finance 14, 559564 (2014)

10. J. Black, E. Wymeersch, K.J. Hopt, G. Ferrarini, Financial Regulation and Supervision: a Post-Crisis Analysis (Oxford University Press, Oxford, UK, 2012) ISBN 9780199660902

11. N.G. Bagautdinova, E.A. Karasik, L.N. Safiullin, G.N. Ismagilova, Journal of Engineering and Applied Sciences 12(19), 4908-4912 (2017)

12. A.A. Ajupov, M.A. Beloborodova, M.G. Sorokina, A.A. Sherstobitova, International Business Management 10(22), 5227-5231 (2016) 